\title{
Peningkatan Kompetensi Teknologi Informasi Berbasis Produk bagi Calon Guru melalui Kegiatan Study Group Prodi Tadris Fisika FTK UIN Mataram
}

\author{
Kurniawan Arizona ${ }^{1} *$ \\ ${ }^{\text {I}}$ Program Studi Tadris Fisika Fakultas Tarbiyah dan Keguruan Universitas Islam Negeri Mataram, Mataram, Indonesia;
}

DOI: https://doi.org/10.29303/ipmsi.v2i2.84

Citation: Arizona, K. 2020. Peningkatan Kompetensi Teknologi Informasi Berbasis Produk bagi Calon Guru melalui Kegiatan Study Group Prodi Tadris Fisika UIN Mataram. Jurnal Pengabdian Masyarakat Sains Indonesia (JPMSI). 2(2):158-163 .

\section{Article history}

Received: November $14^{\text {th }} 2020$

Revised: December $15^{\text {th }} 2020$

Accepted: December $28^{\text {th }} 2020$

*Corresponding Author:

Kurniawan Arizona, UIN

Mataram, Mataram, Indonesia

Email:

arizona@uinmataram.ac.id
Abstrak: Kompetensi di bidang teknologi informasi di Era Revolusi Industri 4.0 menjadi suatu keniscayaan terutama bagi seorang calon pendidik. Tujuan kegiatan pengabdian kepada masyarakat ini adalah untuk mengasah kompetensi teknologi informasi di bidang pendidikan bagi calon guru di Prodi Tadris Fisika FTK UIN Mataram dengan berbasis produk. Kegiatan ini telah dilaksanakan pada tanggal 11 September sampai 9 Oktober 2019 di Ponpes Darul Qur'an (Kampus Relokasi UIN Mataram). Peserta kegiatan terdiri atas calon guru (mahasiswa semester V dan VII Prodi Tadris Fisika FTK UIN Mataram). Materi pengabdian terdiri atas 1) penggunaan Google Classroom, 2) pembuatan video pembelajaran, 3) blog pembelajaran, 4) media poster (leaflet) dan 5) penyusunan soal berbasis komputer (CBT). Pengabdian dilakukan melalui beberapa tahapan yaitu pemberian materi setiap pekan, pendampingan dalam bentuk praktik langsung, penugasan, dan penilaian terhadap produk yang telah dilakukan. Setiap peserta dibagi menjadai beberapa kelompok untuk mengurai keterbatasan peserta yang tidak memiliki laptop atau smartphone. Di akhir pengabdian peserta diberikan form isian melalui Google Form sebagai bahan evaluasi pelaksaan study group. Berdasarkan analisis respon peserta terhadap kegiatan study group, rata-rata peserta memberi tanggapan dengan kategori sangat baik. Produk yang dihasilkan dalam kegiatan pengabdian ini yaitu Blog Prodi Tadris Fisika, Channel Youtube Prodi Tadris Fisika, video pembelajaran, poster (leaflet) pebelajaran dan soal CBT fisika.

Kata Kunci: kompetensi teknologi informasi, study group, berbasis produk

\section{Pendahuluan}

Kompetensi calon guru yang memiliki daya saing patut menjadi prioritas utama khusunya di Era Revolusi Industri 4.0. Terutama kompetensi dalam bidang teknologi informasi (IT), yang semestinnya menjadi bekal setiap pendidik agar bisa tetap eksis di zaman digital (Arizona, 2020). Digitalisasi pembelajaran sudah berkembang dengan pesatnya, mulai dari pembelajaran online, berbagai video pembelaran yang dapat diakses di Channel YouTube, blog atau website pembelajaran, media poster (leaflet), dan pembuatan soal atau tes berbasis komputer sudah mulai banyak diaplikasikan. Perkembangan ini tentunya patut untuk menjadi perhatian dan bahan intropeksi setiap pendidik, sudahkah kompetensi ini dimiliki oleh setiap calon guru.

Sayangnya tidak semua mahasiswa yang calon guru terutama mahasiswa semester atas (Semester V dan VII) di Prodi Tadris Fisika cakap dalam bidang ini. Kompetensi Mahasiswa Prodi Tadris Fisika masih kurang dalam pengaplikasian teknologi informasi terutama aplikasi yang berbasis komputer. Data empiris yang fundamental terhadap kenyataan ini adalah mahasiswa dalam pembuatan instrumen maupun media pembelajaran sebagai 
Arizona, Jurnal Pengabdian Masyarakat Sains Indonesia 2020, 2 (2):158-163. DOI : https://doi.org/10.29303/jpmsi.v2i2.84

tugas mata kuliah atau bahan tugas akhir masih belum optimal.

Kemampuan mahasiswa Prodi Tadris Fisika FTK UIN Mataram kurang terampil dalam pemanfaatan komputer (teknologi informasi) dalam pembelajaran disebabkan beberapa hal diantaranya, 1) sarana dan prasarana akses laboratorium komputer yang belum memamadai, 2) metode pembelajaran yang masih kurang efektif dan efisien, 3) penguasan IT mahasiswa masih belum optimal, 4) ketersediaan alat dan media pembelajaran yang belum memadai, dan 5) relokasi gedung perkuliahan akibat gempa yang menyebabkan akses sumber belajar seperti perpustakaan kurang maksimal (Arizona, 2020).

Oleh karena itu perlu ada langkah yang efektif dan efesien untuk memfasilitasi mahasiswa calon guru di dalam meningkatkan kompetensi IT mereka, khususnya dalam menunjang kompetensi mereka dalam pembuatan instrumen dan media pembelajaran berbasis komputer. Banyak cara yang telah dilakukan berdasarian hasil pengabdian dan riset di antaranya pemberian workshop/pelatihan, pendampingan, short course, dan masih banyak metode dan pendekatan lainnya. Dalam pengabdian ini, pengabdi memilih mekanisme pembuatan kegiatan study group berbasis produk yang bekerjasama dengan Himpunan Mahasiswa Program Studi (HMPS) Prodi Tadris Fisika agar kegiatan ini terus berlangsung sesuai dengan kebutuhan kompetensi yang ingin dipelajari. Pada tahapan ini pengabdi lebih fokus untuk melatih kompetensi mahasiswa di bidang teknologi informasi yang sangat penting untuk dimiliki oleh setiap mahasiswa calon guru. Sehingga melalui kegiatan pengabdian ini kompetensi mahasiswa calon guru di bidang teknologi informasi meningkat dan ada produk pembelajaran yang dihasilkan.

\section{Metode}

Pelaksanaan pengabdian secara umum terbagi menjadi tiga tahapan yaitu 1) persiapan, 2) pelaksanaan dan 3) umpan balik. Tahapan persiapan meliputi a) observasi tempat kegiatan penabdian, b) pengumpulan informasi, c) Diskusi dengan Ketua, sekretaris, dosen sejawat dan Ketua Himpunan Mahasiswa Program Studi Tadris Fisika, d) Sosialisasi dan pembukaan pendaftaran anggota Study Group Program Studi Tadris Fisika, dan e)
e-ISSN : 2715-2537

p-ISSN : 2715-2545

penyiapan media dan sarana pendukung kegiatan pengabdian.

Tahapan pelaksanaan terdiri dari a) Pemberian kata pengantar terkait dengan kegiatan Study Group Prodi Tadris Fisika, b) pembentukan kelompok kecil, c) Pengenalan dan Penggunaan Aplikasi Google Classroom, d) Pelatihan Pembuatan video pembelajaran, e) Pembelajaran Pembuatan Blog, f) Pelatihan pembuatan poster/leaflet, dan g) Pelatihan penyusunan soal berbasis CBT dengan quiz creator. Pada setiap tahapan pemberian materi peserta study group mendapatkan pelatihan dan bimbingan langsung oleh pengabdi dan pemateri lainnya. Di akhir sesi pelatihan, setiap peserta diberikan tugas atau proyek secara berkelompok yang harus mereka kerjakan dan dipresentasikan pada pertemuan berikutnya.

Kegiatan pengabdian dalam bentuk study Group Prodi Tadris Fisikad diakhiri dengan pemberian umpan balik pelaksanaan Study Group melalui angket yang diberikan pada google form. Setiap peserta mengisi form tersebut sebagai evaluasi evektifitas pelaksanaan pengabdian. Produk terbaik yang dihasilkan akan di-publish di Blog dan Channel Youtube Prodi Tadris Fisika.

\section{Hasil dan Pembahasan}

Hasil koordinasi dan diskusi pada tahapan awal kegiatan pengabdian ini memberi respon positif dari berbagai pihak mulai dari Ketua, Sekretaris, Ketua HMPS Prodi Tadris Fisika dan rekan dosen lainnya.
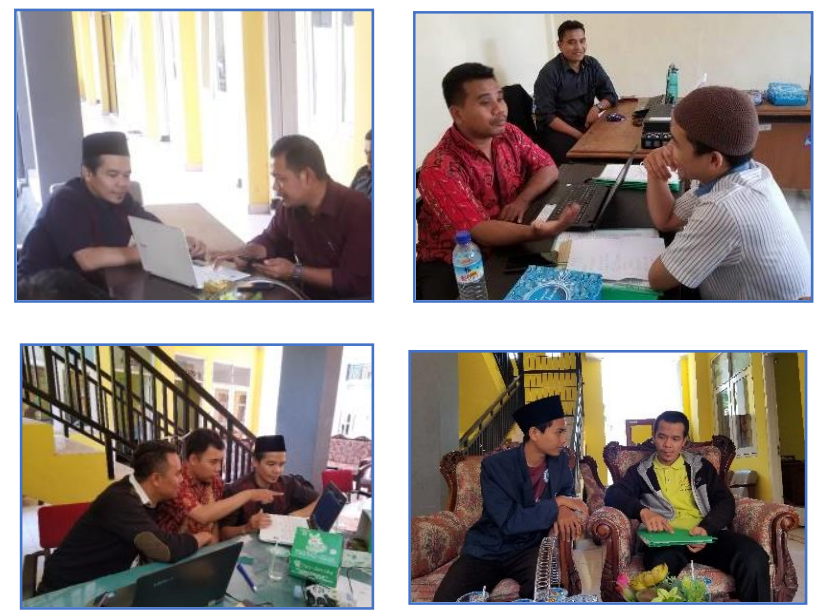

Gambar 1.Koordinasi dan diskusi dengan Kaprodi, Sekprodi , Teman Sejawat dan Ketua HMPS Prodi Tadris Fisika 
Arizona, Jurnal Pengabdian Masyarakat Sains Indonesia 2020, 2 (2):158-163. DOI : https://doi.org/10.29303/jpmsi.v2i2.84

Diharapkan dari kegitan study group ini dapat menghasilkan produk yang dapat digunakan sebagai alternatif kesedian media dan informasi tentang Prodi Tadris Fisika FTK UIN Mataram. Hal tersebut tentunya menjadi tantangan tersendiri untuk melakukan kegiatan Study Group Prodi Tadris Fisika yang berbasis produk seperti Blog Tadris Fisika, Channel Youtube Prodi Tadris Fisika yang menampung berbagai video pembelajaran yang dihasilkan, instrumen tes CBT dan poster (leaflet) pembelajaran/profil Prodi Tadris Fisika.

Tahapan selanjutnya pengabdi melakukan sosialisasi sekaligus membuka pendaftaran kepada mahasiswa untuk mengikuti Study Group Prodi Tadris Fisika. Tercatat ada 26 mahasiswa dari semester V dan VII yang mengikuti kegiatan ini.
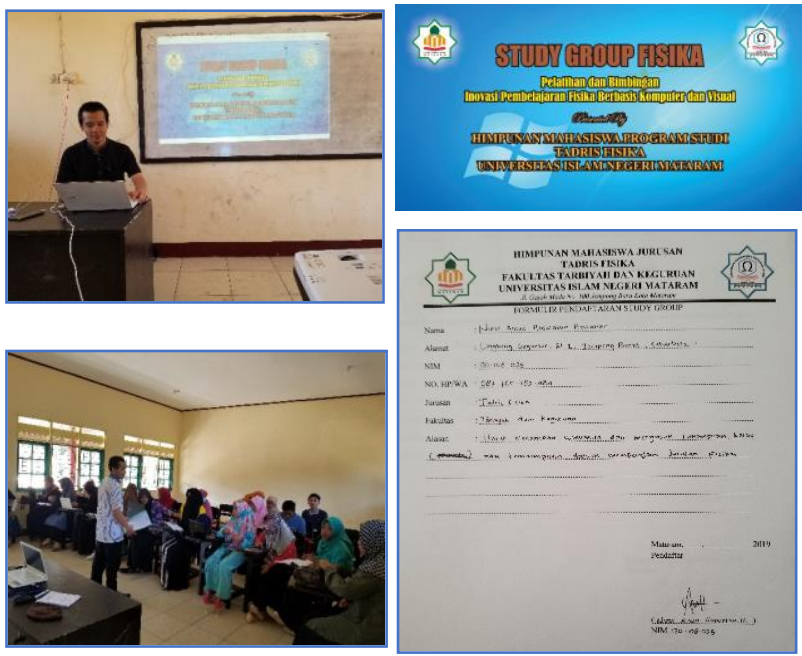

Gambar 2. Sosialisasi dan Form Pendaftaran study group

Sebelum melakukan kegitan study group, setiap peserta mengisi daftar hadir dan dibagi menjadi kelompok kecil untuk memudahkan mereka dalam mengerjakan latihan dan tugas yang diberikan. Ada 5 materi yang disampaikan dan dilatih dalam kegiatan Study Group Prodi Tadris Fisika yaitu 1) Pengenalan dan Penggunaan Aplikasi Google Classroom, 2) Pelatihan Pembuatan video pembelajaran, 3) Pembelajaran Pembuatan Blog, 4) Pelatihan pembuatan poster/leaflet, dan 5) Pelatihan penyusunan soal berbasis CBT dengan quiz creator. Berikut tahapan-tahapan kegiatan yang teah terlaksana sebagaiamana yang tersaji pada Gambar 3.

Kegiatan Study Group Program Studi Tadris Fisika FTK UIN Mataram memberikan manfaat bagi mahasiswa untuk meningkatkan

e-ISSN : 2715-2537

p-ISSN : 2715-2545

kompetensi diantaranya: 1) meningkatkan keterampilan mahasiswa calon guru dalam pembelajaran fisika khususnya pada bidang teknologi informasi sebagai penunjang kompetensi mereka sebelum menyelesaikan tugas akhir dan terjun di dunia kerja, 2) sebagai suplemen pembelajaran dan skill tambahan bagi mahasiswa calon guru sehingga dapat memahami seluk beluk pengajaran inovatif lebih dini, 3) meningkatkan pengalaman mahasiswa calon guru dalam proses belajar mengajar, dan 4) membuka cakrawala berpikir mahasiswa calon guru untuk menemukan suatu alternatif inovasi pembelajaran yang sesuai dengan karakteristik pembelajaran yang diajarkan.

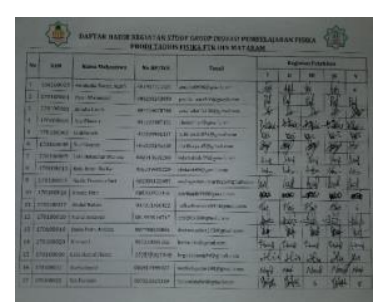

Pengisian Daftar Hadir

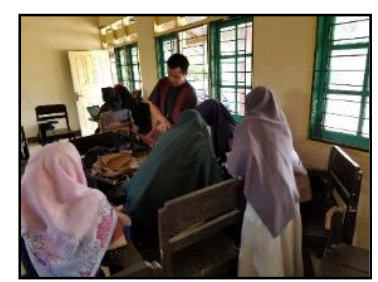

Pelatihan Video Pembelajaran

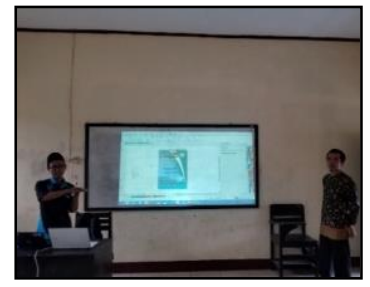

Pelatihan Pembuatan

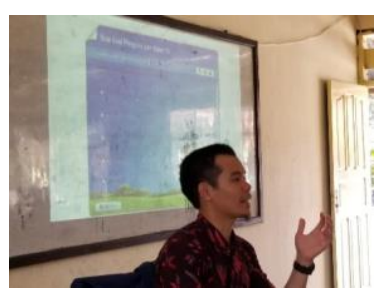

Pelatihan Pembuatan Soal CBT

Gambar 3. Tahapan Pelaksanaan Kegiatan Pelatihan dan Bimbingan Pengabdian

Beberapa kendala dalam kegiatan Study Group Prodi Tadris Fisika yaitu tidak semua mahasiswa memiliki smartphone dan laptop. 
Arizona, Jurnal Pengabdian Masyarakat Sains Indonesia 2020, 2 (2):158-163. DOI : https://doi.org/10.29303/jpmsi.v2i2.84

Sarana WIFI yang masih kurang (koneksi jaringan terkendala). Solusi yang diberikan dengan cara mendorong mahasiswa bekerja secara kolaboratif dan menggunakan paket data pribadi. Sebagaimana yang diungkapkan Arends (2008) yang dikutip Harjono, dkk. (2015) peserta didik yang bekerja dalam situasi pembelajaran kolaboratif didorong untuk bekerjasama dan saling tergantung satu sama lain untuk mencapai satu penghargaan bersama. Mereka akan saling berbagi penghargaan tersebut seandainya mereka berhasil menjadi kelompok terbaik.

Di samping pelatihan dan bimbingan secara langsung (luring) kegiatan Study Group Prodi Tadris Fisika juga dilakukan dengan pembelajaran online menggunakan apliakasi Google Classroom. Banyak metode, strategi, pendekatan, model, taktik maupun teknik yang dapat diterapkan dalam proses transfer ilmu di era yang serba canggih ini. Salah satunya dengan memanfaatkan pembelajaran online (Marikar, 2016).

Ketepatan dalam memilih strategi maupun metode tentunya menjadi suatu keharusan dilakukan oleh seorang pendidik sesuai dengan karakteristik materi yang akan disampaikan. Penggunaan aplikasi Google Classroom dalam pelakasanaan pengabdian terbukti efektif untuk mengantarkan mahasiswa mencapai kompetensi yang diharapkan. Sesuai dengan hasil penelitian Sabran dan Sabara (2018) menyatakan pembelajaran melalui aplikasi Google Classroom secara keseluruhan cukup efektif dalam proses pembelajaran. Hasil yang sama dikemukakan Abidin, dkk (2020) bahwa ada pengaruh signifikan dari kemudahan, kemanfaatan, dan kualitas layanan Google Classroom terhadap efektivitas pembelajaran.

Berdasarkan hasil respon dari 26 peserta terhadap kegiatan study group yang telah dilaksanakan melalui aplikasi Google Form mendapatkan penilaian kategori baik sekali dengan nilai rata-rata tanggapan pada keseluruhan item angket 93 sebagaimana yang tersaji pada Gambar 4 .

Banyak saran dan masukan yang beragam diberikan oleh peserta. Secara keseluruhan mereka memberikan respon yang positif terhadap pelaksanaan Study Group Prodi Tadris Fisika. Setiap peserta berharap kegiatan ini terus dilaksanakan dan ditingkatkan baik dari segi kualitas dan kuantitas untuk tema-tema atau materi yang lain. Merekapun menginginkan agar setiap
e-ISSN : 2715-2537

p-ISSN : 2715-2545

peserta difasilitasi dengan ketersediaan laptop atau komputer yang memadai di kampus agar mereka dapat menggunakannya dalam praktik terutama bagi mahasiswa yang tidak mampu membeli laptop.

Beberapa hal yang patut dibenahi dalam kegiatan study group berdasarkan respon peserta yaitu 1) saat proses penyampaian materi, sebaiknya media atau slide materi yang ditampilkan lebih dekat posisinya dengan peserta agar lebih jelas terlihat, 2) penjelasan yang disampaikan agar lebih detail, dan 3) penyampaian materi tidak terlalu cepat ritmenya, dan 4) posisi tempat duduk diatur lebih baik.

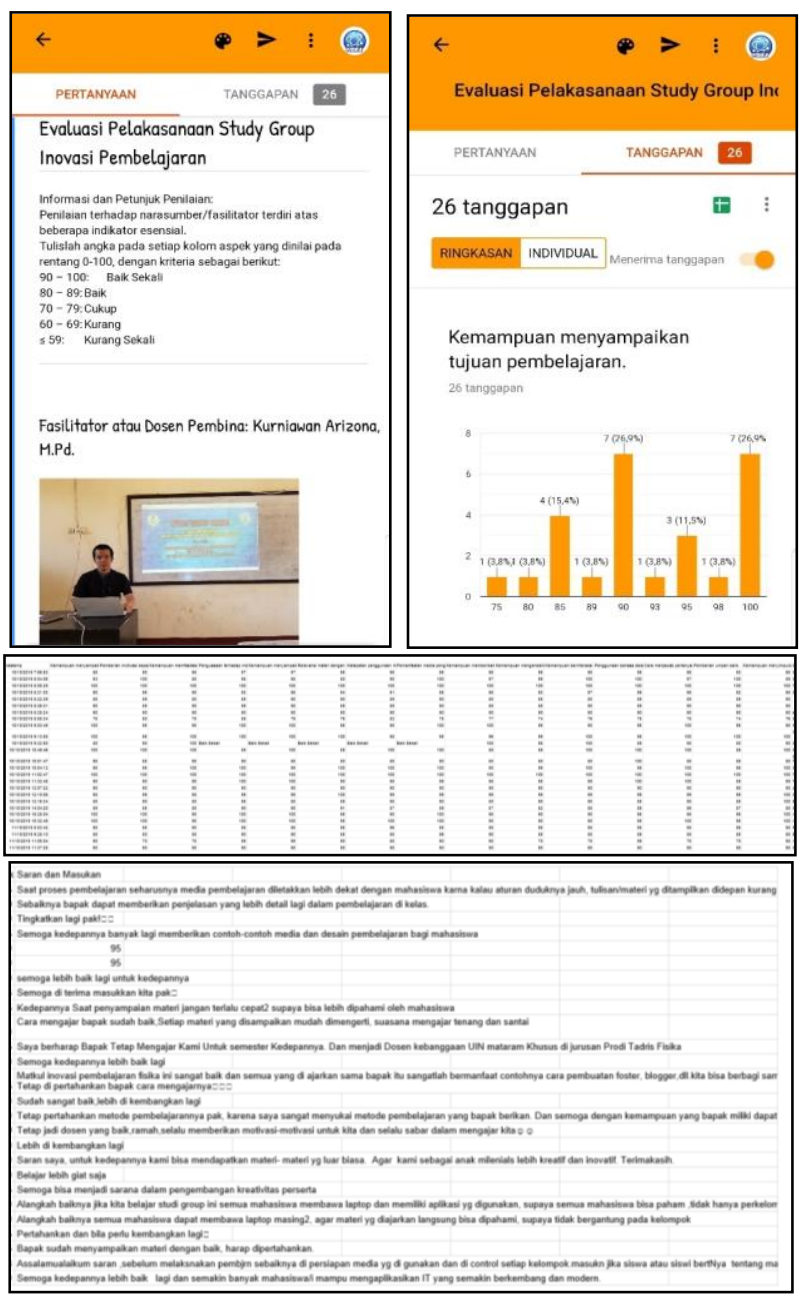

Gambar 4. Tanggapan Pelaksanaan Study Group oleh Peserta

Beberapa produk yang dihasilkan dari kolaborasi pengabdi dan peserta Study Group Prodi Tadris Fisika FTK UIN Mataram yaitu Blog Prodi Tadris Fisika, Channel YouTube Prodi Tadris Fisika, video pembelajaran/profil, poster (leaflet) pebelajaran dan soal CBT fisika. Beberpa link yang 
Arizona, Jurnal Pengabdian Masyarakat Sains Indonesia 2020, 2 (2):158-163. DOI : https://doi.org/10.29303/jpmsi.v2i2.84

dapat diakses dari hasil produk kegiatan study group yang telah dilaksanakan tersaji pada Tabel 1. Diharapkan dengan produk yang telah ada memberi manfaat lebih untuk menjadi role model yang bisa diamati, adopsi, modifikasi dan dikembangkan menjadi lebih baik. Akhirnya semoga kegiatan pengabdian ini memberi manfaat untuk semua khususnya peserta dan Civitas Akademika Program Studi Tadris Fisika FTK UIN Mataram.

Tabel 1. Hasil Produk Study Group Prodi Tadris Fisika

\begin{tabular}{|c|c|c|}
\hline No & $\begin{array}{l}\text { Contoh } \\
\text { Produk } \\
\end{array}$ & Link Download \\
\hline 1 & $\begin{array}{l}\text { Blog Prodi } \\
\text { Tadris Fisika }\end{array}$ & http://bit.ly/Blog_TadrisFisikaFTKUINMA \\
\hline 2 & $\begin{array}{l}\text { Youtube } \\
\text { Prodi Tadris } \\
\text { Fisika }\end{array}$ & http://bit.ly/YTubeTFisikaFTKUINMA \\
\hline 3 & Video Scribe & $\underline{\text { http://bit.ly/Video_Scribe_TFisika }}$ \\
\hline 4 & $\begin{array}{l}\text { Video } \\
\text { Windows } \\
\text { Live Movie } \\
\text { Maker }\end{array}$ & $\underline{\text { http://bit.ly/WindowsLiveMovie_Fisika }}$ \\
\hline 5 & $\begin{array}{l}\text { Poster } \\
\text { Pembelajaran }\end{array}$ & $\underline{\text { http://bit.ly/Poster_TFisikaFTKUINMA }}$ \\
\hline 6 & $\begin{array}{l}\text { Contoh Soal } \\
\text { CBT Fisika }\end{array}$ & $\underline{\text { http://bit.ly/CBT InovasiFisika }}$ \\
\hline
\end{tabular}

\section{Kesimpulan}

Kegiatan pengabdian telah dilaksanakan sesuai dengan tahapan yang telah direncanakan. Kegiatan pengabdian dilakukan melalui beberapa tahapan yaitu 1) pemberian materi setiap pekan, 2) pendampingan dalam bentuk praktik langsung, 3) penugasan untuk menghasilkan produk, dan 4) penilaian terhadap produk yang telah dilakukan. Setiap peserta dibagi menjadi beberapa kelompok untuk mengurai keterbatasan peserta yang tidak memiliki laptop atau smartphone. Di akhir pengabdian peserta diberikan form isian melalui Google Form sebagai bahan evaluasi pelaksaan study group. Berdasarkan analisis respon peserta terhadap kegiatan study group, rata-rata peserta memberi tanggapan kategori sangat baik. Produk yang dihasilkan dalam kegiatan pengabdian ini yaitu Blog Prodi Tadris Fisika, Channel Youtube Prodi Tadris Fisika, kumpulan video pembelajaran,
e-ISSN : 2715-2537

p-ISSN : 2715-2545

poster (leaflet) pebelajaran dan soal CBT fisika yang dapat menjadi role model untuk kegiatan selanjutnya.

\section{Saran}

Beberapa hal yang patut dibenahi dalam kegiatan Study Group berdasarkan respon peserta yaitu 1) saat proses penyampaian materi sebaiknya media atau slide materi yang ditampilkan lebih dekat posisinya dengan mahasiswa agar lebih jelas terlihat, 2) penjelasan yang disampaikan agar lebih detail, dan 3) penyampaian materi tidak terlalu cepat ritmenya, dan 4) aturan posisi tempat duduk diatur lebih baik.

\section{Ucapan Terima Kasih}

Penulis mengucapkan terima kasih kepada Civitas Akademika Prodi Tadris Fisika FTK UIN Mataram terutama Kaprodi, Sekretaris Prodi, rekanrekan dosen dan semua mahasiswa yang telah berpastisipasi aktif dalam kegiatan pengabdian ini.

\section{Daftar Pustaka}

Abidin, Z., Rumansyah, R. \& Arizona, K. 2020. Pembelajaran Online Berbasis Proyek Salah Satu Solusi Kegiatan Belajar Mengajar di Tengah Pandemi Covid-19. Jurnal Ilmiah Profesi pendidikan, 5(1), 64-70.

http://www.jipp.unram.ac.id/index.php/jipp/a rticle/view/111/99

DOI: https://doi.org/10.29303/jipp.v5i1.111

Arizona, K. 2020. Inovasi Pembelajaran Fisika di Era Revolusi Industri 4.0. Mataram: Sanabil.

Arizona, K. 2020. Elevating Students'competence Based Ict In The Era Of Industrial Revolution 4.0. Journal of Teaching and Learning Physics, 5(2), 48-59.

https://journal.uinsgd.ac.id/index.php/jtlp/arti cle/view/7987

DOI:

https://doi.org/10.15575/jotalp.v5i2.7987

Harjono, A., Jufri, A.W., \& Arizona, K. 2015. Implementasi Media Tiga Dimensi Kemagnetan Berbasis Inkuiri Melalui Strategi Kooperatif Terhadap Sikap Ilmiah Siswa. Jurnal Pendidikan Fisika dan Teknologi, 1(1), 15-23. 
Arizona, Jurnal Pengabdian Masyarakat Sains Indonesia 2020, 2 (2):158-163.

http://jurnalfkip.unram.ac.id/index.php/JPFT/ article/view/23

DOI: http://dx.doi.org/10.29303/jpft.v1i1.231

Sabran \& Sabara, E. 2018. Keefektifan Google Classroom sebagai Media Pembelajaran. Prosiding Seminar Nasional Lembaga Penelitian Universitas Negeri Makassar "Diseminasi Hasil Penelitian Melalui Optimalisasi Sinta dan Hak Kekayaan Intelektual", 122-125

https://ojs.unm.ac.id/semnaslemlit/article/vie $\mathrm{w} / 8256$

Marikar, F. M. 2016. Effectiveness of MOODLE in Education System in Sri Lankan University. International Journal of Modern Education and Computer Science, 8(2), 54. 